REVISTA X, Curitiba, volume 14, n.3,121-137, 2019.

\title{
RAÇA E RESISTÊNCIA AO RACISMO EM ATIVIDADES DE LÍNGUA INGLESA NO SUL DA BAHIA
}

Race and resistance to racism in English language activities in South Bahia

Gabriel NASCIMENTO (UFSB/USP) ${ }^{1}$

RESUMO: Este trabalho trata do uso de atividades que abordam questões raciais nas aulas de língua inglesa na Universidade Federal do Sul da Bahia (UFSB). Sendo uma instituição nova, a UFSB tem, em seu primeiro ciclo, disciplinas de língua inglesa que permitem desenvolver o aprendizado da oralidade junto com a leitura e escrita. Neste artigo tomamos como base os estudos já realizados sobre identidades sociais no ensino de línguas, e a perspectiva racial que engloba o sentido de raça enquanto signo de resistência. Do ponto de vista metodológico, este trabalho traz dados de uma pesquisa que teve como corpus as atividades realizadas pelos estudantes por meio da proposição de textos e temas pelo professor/pesquisador sobre a questão racial na região. Os dados revelam manifestações dos estudantes que debatem e contextualizam o racismo, a partir dos textos estudados, e através das questões raciais na própria região, de maneira que eles se interessaram mais pela língua inglesa no processo e puderam abordar aspectos que fazem parte do seu cotidiano

PALAVRAS-CHAVE: Raça; Língua inglesa; Universidade Federal do Sul da Bahia.

ABSTRACT: This paper discusses the use of activities that address racial issues in English language classes at the Federal University of South Bahia (UFSB). Being a new institution, the UFSB offers for its first cycle studies English language courses that work on skills such as listening, speaking, reading and writing. However, in this research I sought to analyze presentations and samples from presentations students carried out which were built on the texts we used in class to analyze racial problems in the region. As results, we found samples of works that debate and contextualize racism, from the texts we discussed concerning racial problems in the region. That worked as a means to encourage students so that they become more interested in the English language and so that they can criticize and analyze issues that are part of their daily lives resisting to racism.

KEYWORDS:Race; English language; Federal University of South Bahia.

\section{INTRODUÇÃO}

O ensino de inglês tem sido permeado por desigualdades sociais e raciais das mais diversas formas, incluindo as hierarquias de gênero e sexualidade (TÍLIO e JÚNIOR, 2014), classe social (SANTOS e MASTRELLA-DE-ANDRADE, 2016) e raça (FERREIRA e CAMARGO, 2013; JORGE, 2016). Neste trabalho nos

\footnotetext{
${ }^{1}$ Professor da Universidade Federal do Sul da Bahia, coordenador do Laboratório de Linguagens da UFSB. Mestre em Linguística Aplicada pela UnB e doutorando em Estudos Linguísticos pela USP. Email: gabrielnasciment.eagle@ @otmail.com
} 
REVISTA X, Curitiba, volume 14, n.3,121-137, 2019.

interessamos na relação entre ensino de línguas e uma perspectiva racial na Linguística Aplicada, que Rosa e Flores (2017) chamam de Raciolinguistic perspective.

Ao usarem Raciolinguistic perspective, os autores politizam o uso da questão racial no ensino de línguas chamando atenção para as desigualdades raciais trazidas nas políticas linguísticas. Numa interface de crítica ao multiculturalismo liberal, Kubota (2004; 2009) afirma que as desigualdades surgem na suposta tentativa de tolerar o negro e o imigrante ao passo em que eles são descritos pela colonialidade como incompetentes ou através do mito falante nativo versus falante não-nativo.

Neste trabalho apresentaremos a possibilidade de resistência racial de estudantes negros e indígenas ${ }^{2}$ ao racismo através de atividades propostas em uma disciplina de língua inglesa na Universidade Federal do Sul da Bahia, de maneira a compreender como a raça é um construto em afirmação, reafirmação e ressignificação através de seu uso crítico em aulas de língua inglesa. Para tanto, inicialmente vamos debater a perspectiva racial a partir de trabalhos em Linguística Aplicada que enfocam a raciolinguistic perspective, que desnaturaliza raça e linguagem a partir das políticas linguísticas de Estado (ROSA e FLORES, 2017), a ideia de elitização do ensino de línguas (FERREIRA e CAMARGO, 2013; NASCIMENTO, 2016), que permite exclusão social e subsequente exclusão das pessoas negras nesse processo, a crítica às políticas que o multiculturalismo liberal tem fomentado através das políticas linguísticas (KUBOTA, 2004) e, por último, as razões dessa relação entre ensino de línguas e racismo nas políticas do colonialismo e do imperialismo (PHILIPSON, 1992; PENNYCOOK, 2002). A seguir, destaco as discussões em Mbembe (2014), para pensar raça enquanto signo de opressão, mas também de resistência. Para contextualizar raça enquanto signo de resistência, uso os argumentos de Moura (2014) e Azevedo (1987) no sentido de desmentir a visão de negritude enquanto identidade passiva no Brasil.

O presente trabalho se constitui através da análise de atividades dos estudantes que tiveram como foco as questões regionais que tratam de raça e etnicidade no contexto do sul da Bahia. Por isso, como metodologia, empreguei os instrumentos de cunho etnográfico, e, de maneira interventiva, propus atividades que tivessem como foco a produção de apresentações e materiais com temas voltados à raça/racismo no sul da Bahia. Os resultados aqui trazidos apontam para implicações positivas nos usos

\footnotetext{
${ }^{2}$ Embora tratemos aqui de estudantes indígenas, neste trabalho não produzimos fortuna crítica e discussão sobre etnicidade dos indígenas, o que ficará para ocasião posterior. O nosso foco aqui é, portanto, a questão racial negra.
} 
REVISTA X, Curitiba, volume 14, n.3,121-137, 2019.

dessas atividades e, como pesquisador/professor, trago as primeiras impressões de maior participação dos alunos nessas aulas, bem como maior interesse na língua inglesa por parte deles, que serão divulgadas em formas de dados em publicações futuras.

\title{
A LINGUÍSTICA APLICADA, O ENSINO DE LÍNGUAS E A PERSPECTIVA RACIAL
}

Embora muitos trabalhos sobre questões raciais no ensino de línguas tenham sido e estejam sendo realizados no campo da Linguística Aplicada, esse ainda é um tema usado como transversal e não estruturante. Como analisam Rosa e Flores (2017), o próprio conceito de língua implica o conceito de raça na produção das chamadas identidades nacionais no âmbito da modernidade. Ou seja:

\begin{abstract}
A construção da raça foi um elemento integrante do projeto nacional e colonial europeu que discursivamente produziu outras raças em oposição ao sujeito burguês europeu superior. [...] Este posicionamento da cidadania europeia como superior à não-cidadania europeia fazia parte de um processo mais amplo de institucionalidade nacional-estadual / colonial [...], uma forma de racialização institucional que impôs a autoridade epistemológica e institucional europeia para as populações colonizadas em todo o mundo como uma justificativa para o próprio colonialismo (ROSA e FLORES, 2017, p. $3)^{3}$.
\end{abstract}

Assim, é possível afirmar os falantes da língua inglesa como uma comunidade imaginada (ANDERSON, 1991), em que o projeto europeu assimilou as línguas como idealização da própria cultura de seu povo no intuito de promover dominação e criar um espírito de consciência nacional na modernidade.

Norton e Toohey (2011) também compreendem a língua como comunidade imaginada à medida que dela emanam poderes coloniais nacionalistas. Eu mesmo observei em trabalho anterior como a língua enquanto comunidade imaginada no Brasil adveio da elitização do ensino de inglês no país:

O enquadre das relações étnicas se dá dentro do imaginário da democracia
racial. Esse imaginário se encontra inserido em nossos mitos fundacionais,
numa relação imbricada com as comunidades imaginadas pelas elites desde
as Capitanias hereditárias. É preciso refletir criticamente a partir de dois
aspectos que aqui são considerados fundamentais: a) a política colonialista
instaurada no Brasil durante séculos; b) a elitização do ensino de língua
inglesa no Brasil e sua caracterização central (NASCIMENTO, 2016, p.542).

\footnotetext{
${ }^{3}$ Minha tradução do trecho "The construction of race was an integral element of the European national and colonial project that discursively produced racial Others in opposition to the superior European bourgeois subject [...] This positioning of Europeanness as superior to non-Europeanness was part of abroader process of national-state/colonial governmentality, a form of governmental racialization that imposed European epistemological and institutional authority on colonized populations worldwide as a justification for European colonialism”.
} 
Em que:

\begin{abstract}
A elitização do ensino de inglês se dá por uma série de fatores, a nosso ver. Primeiro, pelo caráter do entendimento da importância da oferta universal do ensino de uma segunda/língua estrangeira no país. Desde o Brasil Colônia, [...], a oferta e criação de cadeiras e vagas para o ensino de língua estrangeira tem [sic] se dado por razões pragmáticas, sempre por causa de alguma área estratégica para o interesse nacional. Em nosso entendimento, para o interesse das elites. Desse modo, a oferta sempre foi entendida como uma política complementar, e não como política em si, sendo monopolizada como instrumento estético ou pragmático pelas elites (NASCIMENTO, 2016, p.544).
\end{abstract}

Ou seja, a língua está dentro e não fora do projeto das identidades nacionais e, portanto, a partir dela as desigualdades raciais se expressam enquanto projeto, de maneira a elitizar identidades e o próprio imaginário do ensino de línguas.

No âmbito da pesquisa científica, Kubota (2004), tem sido uma das vozes mais importantes no sentido de desnudar a posição racista do multiculturalismo liberal, na maneira em que ele usa a ideia de tolerância, mas continua produzindo desigualdades. Em suas análises, ela tem demonstrado o quanto os problemas do neoliberalismo e do multiculturalismo liberal têm avançado no ensino de segunda língua, como aponta a seguir:

Uma das concepções mais problemáticas que os professores de segunda língua precisam desmascarar é o essencialismo cultural e étnico e a construção da identidade. Como discutido anteriormente, é importante entender que as imagens do Outro e do Eu não são nem naturais nem neutras, mas são construídas discursivamente e são influenciadas por, e reforçando o pensamento binário interno, relações desiguais de poder (KUBOTA, 2004, p. 44$)^{4}$.

Assim, raça e racialidade ${ }^{5}$ se expressam a partir da linguagem nas políticas geopolíticas, econômicas e linguísticas, como quero aqui demonstrar. Em complemento às análises de como o ensino de línguas reproduz hierarquias de poder, Philipson (1992) e Pennycook (2002) centram suas análises no imperialismo linguístico do inglês, no

\footnotetext{
${ }^{4}$ Tradução minha do trecho "One of the most problematic conceptions that second language educators need to debunk is cultural and ethnic essentialism and identity construction. As discussed earlier, it is important to understand that images of the Other and Self are neither natural nor neutral but are discursively constructed and are influenced by, and reinforce binary thinking within, unequal relations of power".

${ }^{5}$ Defino racialidade, como base em Appiah (1997), como o produto da ideologia de racialização fabricada pelo racialismo ocidental, que definiu os negros, indígenas e todos os não-brancos a partir da ideia de raça enquanto definia os brancos como humanos. A racialidade, ao meu ver, é produto da linguagem quando esta é usada para nomear, excluir e produzir silenciamentos ao produzir raça enquanto conceito que exclui, silencia e mata.
} 
REVISTA X, Curitiba, volume 14, n.3,121-137, 2019.

caso do primeiro, e dos discursos do colonialismo que são reproduzidos através do inglês como língua franca no caso do segundo.

Também nesse sentido, no caso do Brasil, Ferreira e Camargo (2013) analisam de forma minuciosa o racismo cordial que é um processo sempre reforçado nos cursos de inglês existentes no país. Para isso, elas mostram que o mito da democracia racial (em que o Brasil supostamente vive uma democracia racial, sem racismo e, portanto, sem discriminação étnica) é difundido nesses cursos sem nenhuma reflexão. Por exemplo, ao apresentar o homem negro, o livro registra apenas um único homem negro, advindo de Angola, revelando o estereótipo sobre a existência de homens negros somente no continente africano, e, ignorando, dessa forma, a população negra do Brasil, que, de acordo com dados coletados pelo Instituto Brasileiro de Geografia e Estatística (IBGE) em seu Censo de 2010, se constitui de mais 52\% dos brasileiros ${ }^{6}$.

Por isso, neste artigo tomaremos a perspectiva racial para desnudar os processos de manutenção do racismo no ensino de línguas de maneira a empoderar identidades resistentes aos processos de desigualdade fundados através da lógica da colonialidade e do capitalismo.

\section{RAÇA ENQUANTO SIGNO DE OPRESSÃO}

O filósofo Achille Mbembe (2014) tem sido uma das vozes mais contundentes do século na crítica às formas como o racismo se mantém e se reconstrói. Uma das coisas fundamentais trazidas por ele é a análise do conceito de raça enquanto signo de opressão. Assim:

[...] Poder predador, poder autoritário e poder polarizador, o capitalismo precisou sempre de subsídios raciais para explorar os recursos do Planeta. Assim o foi e assim o é, ontem e hoje, ainda que atualmente esteja a colonizar o seu próprio centro, e que as perspectivas de um devir-negro do mundo nunca tenham sido tão evidentes (MBEMBE, 2014, p. 299).

Portanto, para ele, a raça é um signo que evoca "um complexo perverso, gerador de medos e de tormentos, de problemas do pensamento e de terror, mas, sobretudo, de infinitos sofrimentos" (MBEMBE, 2014, p. 25), e por isso mesmo:

[...] A raça não passa de uma ficção útil, de uma construção fantasista ou de uma projeção ideológica cuja função é desviar a atenção dos conflitos antigamente entendidos como verossímeis - a luta de classes ou a luta dos sexos, por exemplo. Em muitos casos, é uma figura autônoma do real, cuja força e densidade podem explicar-se pelo seu caráter extremamente móvel,

${ }^{6}$ Para mais informações, por favor clique em http://censo2010.ibge.gov.br/ 
REVISTA X, Curitiba, volume 14, n.3,121-137, 2019.

inconstante e caprichoso (MBEMBE, 2014, p. 27).

A raça, portanto, é uma ficção ditada pela colonialidadade e assumida por ela para fins de dominação. Isso quer dizer que, ao usar a linguagem, o colonizador nomeou o colonizado com fins de dominá-lo. Por isso, é importante afirmar que o colonizador branco funda o conceito de raça no ocidente, sendo que, segundo Mbembe (2014), o uso da palavra negro, por exemplo, passa a ser mais comum a partir do uso do colonizador. Isso quer dizer que os negros africanos não se chamavam de negros antes da chegada do colonizador e que esse uso se deu no sentido de essencializar as mais diversas etnias africanas no sentido de dominá-las.

\section{RAÇA ENQUANTO RESISTÊNCIA}

No entanto, raça também é resistência, naquilo de Tílio (2010) nomeou, pensando exclusão no ensino de línguas de maneira geral, como identidades de resistência, ao estudar como é possível resistir aos processos de essencialização a partir do livro didático de inglês. Ao discutir esse aspecto, o autor explora a possibilidade dos estudantes, ao terem acesso ao livro didático, de não só se submeterem ou se assimilarem ao conteúdo excludente do livro, mas também de produzir resistência ao conteúdo por ele abordado.

Mbembe (2014), por exemplo, trata do devir-negro do mundo, ao apresentar o aparente processo em que o mundo pós-industrial chega a uma crise epistêmica do humanismo e de onde surge a raça como lugar de luta contra a racialização, permitindo o surgimento de identidades de resistência. Ou seja, o devir-negro do mundo é também um mundo por vir liberto do peso da raça e dos ressentimentos por ela criados. Porém, não é possível alcançar um devir-negro sem conhecer de maneira absolutamente profunda os meandros do que o Ocidente instituiu enquanto raça.

A seguir trataremos de formas como a negritude foi construída na história não oficial do Brasil de maneira não-passiva e, portanto, enquanto resistência às políticas da colonialidade, para delinear como as identidades raciais podem atuar enquanto identidades resistentes, ao passo que o pensamento social brasileiro a usou para impor uma ideia de passividade do povo negro.

\section{O mito do negro passivo: entre as ondas negras, o medo branco e as rebeliões na senzala}


REVISTA X, Curitiba, volume 14, n.3,121-137, 2019.

Os maiores problemas do mito da democracia racial entre nós tem sido uma série de crenças que não mais estão apenas nas páginas dos livros dos mais reconhecidos sociólogos brasileiros, mas também no imaginário popular, graças a governos progressistas e conservadores.

Assim, por exemplo, a Era Vargas foi fundamental para fazer vigorar a idealização de uma unidade morena ${ }^{7}$ e exaltação da miscigenação como retrato de uma democracia racial no país. Porém, como buscaremos demonstrar aqui, a raiz dessa idealização vem de bem antes.

Portanto, aqui usamos como base a pesquisa de dois historiadores negros brasileiros. São eles Clóvis Moura, em Rebeliões na Senzala: quilombos, insurreições, guerrilhas e Célia Maria Marinho de Azevedo (1987) em Onda negra, medo branco: o negro no imaginário das elites- século XIX.

Esses dois estudiosos se complementam de muitas formas, mas principalmente porque: 1) Clóvis Moura é aqui considerado como principal historiador das rebeliões e insurreições dos negros brasileiros durante os quase 4 séculos de escravidão e, portanto, o representante da ideia de história do povo negro narrada pelo povo negro e com o protagonismo do povo negro; 2) Célia Maria Marinho de Azevedo é a pesquisadora responsável por investigar a mentalidade das elites sobre o negro, permitindo compreender como as elites brancas do século XIX pensavam os negros brasileiros.

Moura (2014) parte de sua análise desconstruindo alguns mitos fundamentais sobre o povo negro brasileiro. Em primeiro lugar a tese de submissão do nosso povo à escravidão, de maneira que, como nos apresenta a história oficial ministrada nas escolas, os primeiros movimentos abolicionistas só vieram acontecer no Sudeste, no século XIX.

Para desconstruir essa tese o autor se debruça sobre os documentos oficiais (Cartas, atas, mandados, sentenças) durante séculos, desde museus, bibliotecas até câmaras e assembleias para precisar uma análise que mostra movimentos de insubordinação durante quase 4 séculos. Para contra-atacar a tese de subordinação do

\footnotetext{
${ }^{7}$ Esse termo foi retirado de Souza (2015), e se refere, tomando como base a minuciosa discussão em Costa (2001), à noção de "brasilidade" construída durante a Era Vargas em que, ao combater os primeiros movimentos de organização negra no século XX (como é caso da Frente Negra Brasileira, um dos primeiros partidos negros do Ocidente), e através de sua leitura empolgada de Casa Grande\&Senzala de Gilberto Freyre, Getúlio Vargas estimula, a partir das políticas de Estado, a celebração da miscigenação racial, e do traço de suposta unidade morena que, para ele, rege o país. Vale salientar, segundo o que pontuo aqui, baseado em Souza (1983), que a ideia de miscigenação no país é brancocêntrica e, se vista do ponto de vista das pessoas negras, representa apagamento e morte, tanto física quanto epistêmica.
} 
REVISTA X, Curitiba, volume 14, n.3,121-137, 2019.

negro ao trabalho escravo (como se o negro tivesse aceitado o processo de maneira passiva), o autor propõe a seguinte tese: onde houve mais concentração de trabalho escravo no país durante esses séculos foi onde houve mais movimentos de insubmissão.

Para confirmar sua tese, analisa o Nordeste e, principalmente, a Bahia. Não por acaso, com o predomínio da cana-de-açúcar, o Nordeste foi a região que mais movimentou a economia brasileira nesses séculos. Permitindo corroborar a tese de Dussel (1993) e Karl Marx (2000) em A Origem do Capital, foi durante esses séculos que Portugal conseguiu se desenvolver enquanto nação no horizonte europeu, graças à colonialidade do poder e, logo, escravidão imposta aos negros ${ }^{8}$. Porém, a cana-deaçúcar não era a única atividade econômica. A própria escravidão, enquanto comércio, passou a ser uma das principais atividades econômicas da colônia. Isso porque, pensando a relação entre comércio e propriedade e o direito de lucrar em cima de uma dada propriedade privada, o sujeito escravizado não "vendia a sua força de trabalho, mas era considerado pelo senhor de escravos um simples instrumento de trabalho, de vez que o direito de propriedade se estendia à própria pessoa do escravo" (MOURA, 2014, p. 120).

Em sua pesquisa, Clóvis Moura destaca que os negros, cativos ou não, pardos ${ }^{9}$ ou pretos, se organizaram em diversas frentes de insubmissão nesses séculos. A primeira forma é a participação ativa em movimentos independentistas, que, embora na história oficial, tenham como líderes os brancos, sempre tiveram participação ativa dos negros. É o caso da Conjuração Baiana, também conhecida como Inconfidência Baiana, Revolta dos Búzios, Revolta dos Alfaiates ou Revolta das Argolinhas, que aconteceu em 1798 na Capitania da Bahia e que neste ano completa 221 anos, bem como na Cabanagem, na Balaiada, na Revolução Farroupilha ou na Inconfidência mineira, como ele protesta:

\footnotetext{
Em outro movimento, a Inconfidência mineira - como na revolta Filipe dos Santos -, o papel do escravo como reserva social do acontecimento ainda não foi suficientemente estudado e esclarecido. Que os inconfidentes, de um modo geral, eram abolicionistas, não há muitas dúvidas. Mas até que ponto esperavam que os escravos aderissem e participassem da revolta é que não está bem claro, embora fosse Minas, na época, um dos maiores focos de quilombos do Brasil (MOURA, 2014, p.122).
}

\footnotetext{
${ }^{8}$ No entanto, em A origem do capital (MARX, 2000), o autor apenas menciona que a passagem do capital primitivo para o capital moderno só pôde se dar graças à instituição de colonização, escravização e dizimação. Esse é um dos raros momentos em que o autor aborda raça. Atribuo mais diretamente a Dussel (1993), como quem parte de Marx e o atualiza.

${ }^{9}$ Uso o termo pardo, embora tenda a enxergar que ele é problemático e também racista, porque é esse termo utilizado pelo autor, por ser da fonte dos documentos analisados na pesquisa.
} 
REVISTA X, Curitiba, volume 14, n.3,121-137, 2019.

No entanto, como Moura (2014) demonstra, o "medo" que os próprios negros se rebelassem antes dos brancos fez com que os líderes da Inconfidência tenham tomado a frente da manifestação antes dos negros, como é dito num trecho dos Autos da Devassa, em que José Álvares Maciel, filho de um capitão-mor de Vila Rica, deixa entrever, ao dizer que "sendo o número de pretos e escravatura do país muito superior aos homens brancos, toda e qualquer revolução que aqueles pressentiam nestes seria motivo para que eles mesmos se rebelassem" (MOURA, 2014, p. 123). Ou seja, embora não dizendo diretamente, a quantidade de quilombos podia, a qualquer momento, provocar em efusão social uma revolta sem precedentes.

Primeiro, é necessário destacar que, como nos disse Moura (2014), a escravidão não acabou por causa de um único movimento abolicionista, mas porque, no auge das lutas abolicionistas do século XIX, os prejuízos perpetrados pelos negros à escravidão eram tantos que o regime escravocrata representava um prejuízo econômico e não um avanço.

Nesse momento, e seguindo a análise de ambos, Azevedo (1789) e Moura (2014), as teses positivistas de racionalidade versus irracionalidade/ trabalho livre versus trabalho escravo tomam conta dos discursos e da produção bibliográfica nacional a serviço de um discurso que ignora o sustentáculo racionalista implantado pelo colonialismo no país, com a participação direta de reformas supostamente modernas, como é o caso da Reforma Pombalina, que visava modernizar o Estado português, mas manteve os privilégios aristocráticos, a escravidão e a dizimação indígena.

A partir de Azevedo (1987), é possível entender o que foi e como se originou o "medo branco" de que falamos anteriormente:

Até meados da década de 1880 temos como enfoque privilegiado a escravidão, o negro e sua rebeldia, o movimento abolicionista e as sucessivas tentativas imigrantistas, enfim, o chamado momento de transição para o estabelecimento pleno do trabalho livre. A partir da data da abolição, o tema da transição deixa subitamente de existir e o negro, como que num passe de mágica, sai de cena, sendo substituído pelo imigrante europeu. Simultaneamente a esta troca de personagens históricos, introduzem-se novos temas, tais como desenvolvimento econômico industrial, urbanização e formação da classe operária brasileira com base numa população essencialmente estrangeira (AZEVEDO, 1987, p.20).

E complementa:

Esta substituição de temas e de enfoques tem sido justificada de modo sucinto e algo taxativo: o negro apático para o trabalho livre e acostumado a coação de um sistema irracional de produção não pode fazer frente a 
REVISTA X, Curitiba, volume 14, n.3,121-137, 2019.

concorrência representada pelo imigrante europeu, trabalhador este já afeito a uma atividade disciplinada, racionalizada e regulada a partir de contrato de compra e venda da forca de trabalho (AZEVEDO, 1987, p.21).

Ou seja, como apresenta a autora, ao binômio positivista, depois fortemente reproduzido pelos sociólogos weberianos, entre eles Sérgio Buarque e Gilberto Freyre, de racionalidade versus irracionalidade/ trabalho livre versus trabalho escravo, constituise em outro: enegrecimento da população brasileira desde os quinhentos versus projeto imigrantista visando branqueamento da população.

Portanto, é possível perceber que, por esse lado, os discursos abolicionistas foram construídos pela colonialidade para silenciar as lutas negras durante séculos. Por isso, a raça enquanto instrumento de transformação é um efetivo de radicalização e combate ao racismo.

\section{NOSSO OBJETO DE ESTUDO: AS ATIVIDADES NAS AULAS DE LÍNGUA INGLESA}

Para esse estudo, que é o recorte de uma pesquisa em andamento, selecionamos excertos de atividades realizadas durante três disciplinas de língua inglesa na Universidade Federal do Sul da Bahia.

A seguir apresento um pouco melhor a Universidade Federal do Sul da Bahia, seu currículo e as disciplinas.

\section{A Universidade Federal do Sul da Bahia}

A Universidade Federal do Sul da Bahia (doravante UFSB) nasceu da pressão de movimentos sociais visando a expansão do ensino superior no sul da Bahia. Pensando a Bahia enquanto estado mais negro do Brasil, o plano orientador da universidade cobre as necessidades de uma universidade fundada em termos de novas epistemologias, ou seja, novas maneiras de conhecer o mundo.

Mesmo com uma grande extensão de populações negras e indígenas, sendo a maioria na região, esses grupos permaneceram sub-representados nas universidades locais do estado ao longo dos anos. Levando em conta essa realidade local, a UFSB nasceu para ser uma universidade afirmativa, conforme reiterado em seu plano orientador:

A UFSB anuncia sua razão de ser, alicerçada na solidariedade e no compartilhamento de conhecimentos, habilidades, desejos, impasses e utopias 
que, em suma, constituem a riqueza imaterial e material que chamamos de saberes ou espírito de uma época. Nessa perspectiva, pauta-se nos seguintes princípios político-institucionais: eficiência acadêmica, com uso otimizado de recursos públicos; compromisso inegociável com a sustentabilidade; ampliação do acesso à educação como forma de desenvolvimento social da região; flexibilidade e criatividade pedagógica, com diversidade metodológica e de áreas de formação; interface sistêmica com a Educação Básica; articulação interinstitucional na oferta de educação superior pública na região e promoção da mobilidade nacional e internacional de sua comunidade (UNIVERSIDADE FEDERAL DO SUL DA BAHIA, 2014, p.10).

Como ação afirmativa, a entrada na UFSB reserva $75 \%$ das vagas para negros, indígenas e egressos de escolas públicas. No entanto, a sua principal ação afirmativa se dá através de sua rede de colégios universitários ${ }^{10}$, em parceria com as escolas da rede estadual de educação, com a reserva de $85 \%$ das vagas para negros, indígenas e egressos de escolas públicas.

Essa medida é responsável por permitir repensar o papel das ações afirmativas através de múltiplas parcerias, a partir dos princípios de inclusão de estudantes locais, negros e indígenas.

Assim, a entrada fornece acesso a cursos de primeiro ciclo (bacharelados interdisciplinares e licenciaturas interdisciplinares, como Bacharelado Interdisciplinar em Artes, Bacharelado Interdisciplinar em Ciências e Bacharelado Interdisciplinar em Humanidades, e cursos interdisciplinares de formação de professores em grandes áreas). Nesse sentido, o currículo é interdisciplinar e conta com disciplinas de língua inglesa permeando toda a formação geral desses estudantes. Para progredir para os cursos de segundo ciclo (bacharelados e cursos de formação de professores em áreas específicas, como Direito, Medicina, Letras, Português, História), os alunos devem cursar, em ordem: 1) Expressão Oral em Língua Inglesa; 2) Compreensão Escrita em Língua Inglesa; e, de acordo com a área, 3) Oficina de Textos em Língua Inglesa.

Com lacunas de compreensão oral e escrita, os alunos entram na disciplina Expressão Oral em Língua Inglesa, que é a primeira de sua formação, solicitando, na maioria das vezes, que as aulas sejam ministradas em Português. Depois disso, os alunos são obrigados a participar da disciplina Compreensão Escrita em Língua Inglesa. A última disciplina, obrigatória para alguns cursos, é Oficina de Textos em Língua Inglesa, com o uso do inglês utilizado para aspectos específicos da grande área de

${ }^{10}$ Esses colégios são unidades acadêmicas da UFSB e não espaços de aplicação, como acontece em diversas universidades mais tradicionais. Neles, os estudantes dessas localidades cursam toda a formação geral do primeiro ciclo de seus cursos. 
REVISTA X, Curitiba, volume 14, n.3,121-137, 2019.

estudos desses estudantes (Artes, Ciências, Humanidades ou Saúde).

\section{OS DADOS DA PESQUISA E ALGUMAS INTERPRETAÇÕES}

Esta pesquisa foi realizada em um período de 12 meses (2017.3, 2018.1 e 2018.2, em que as 3 disciplinas foram oferecidas) com 40 alunos $^{11}$ aproximadamente em cada classe. Coletei dados das disciplinas ao propor algumas atividades relacionadas às questões regionais, incluindo aspectos étnicos e raciais.

Em Expressão Oral em Língua Inglesa, dividi a sala em grupos com temas gerais e solicitei que pensassem sempre a interlocução regional desses temas. Foi o caso, por exemplo, de Occupations, Jobs and Professions ${ }^{12}$, em que pedi que escolhessem tanto profissões de formação universitária como as regionais (a exemplo de pescador, vendedor da feira etc.). O grupo que ficou com o tema Grocery shop ${ }^{13}$, produziu uma réplica de uma feira popular na sala, misturando frutas regionais e não regionais e encenaram o papel dos vendedores de feira ${ }^{14}$ falando inglês, como se pode ver a seguir:

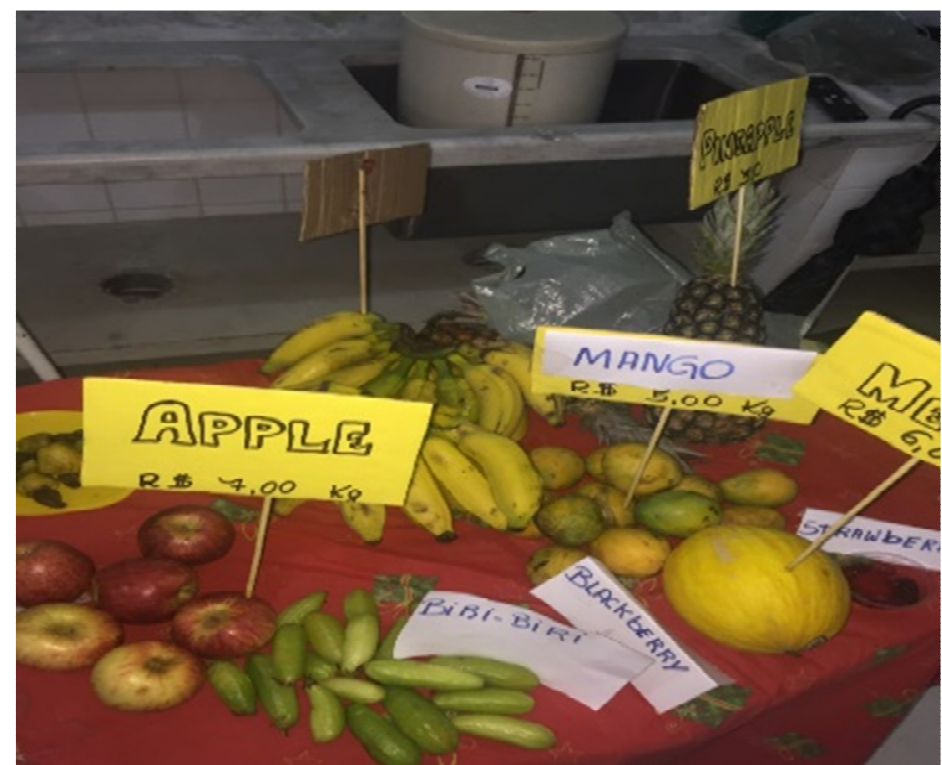

Figura 1- Réplica de uma feira na disciplina Expressão Oral em Língua Inglesa

Por exemplo, Biri-biri é uma fruta muito conhecida na região. Ela deriva da Ásia, mas na região é usada para muitos pratos, como a moqueca de peixe da Bahia, o molho de pimenta, o cuidado com a roupa ou como remédio. Eles escolheram não

\footnotetext{
${ }^{11}$ A maioria dos alunos nessas turmas eram negros ou indígenas.

12 Ocupações, empregos e profissões.

${ }^{13}$ Quitanda, mercearia.

${ }^{14}$ A feira é um fenômeno particularmente muito popular no Nordeste do país. Embora o termo em inglês não queira dizer "feira", a própria versão utilizada pelos estudantes produz espaço de resistência e negociação da identidade linguística de onde eles vêm.
} 
REVISTA X, Curitiba, volume 14, n.3,121-137, 2019.

traduzir a maneira como as pessoas da Bahia batizam essa fruta, "Biri-biri", para proteger a ideia de pertença e identidade. Embora tenha havido a sugestão sobre alguns desses termos de maneira geral, a escolha de não traduzir teve a palavra dos estudantes como decisão final. Assim, eles me consultaram anteriormente sobre as traduções que não foram capazes de fazer e eu sugeri que eles valorizassem as identidades regionais primeiro. Dessa forma, eles próprios decidiram traduzir as frutas mais universais e apresentaram as frutas locais em Português brasileiro.

Além disso, em Compressão Escrita em Língua Inglesa eu usei como texto alguns artigos de opinião, matérias jornalísticas e artigos científicos. Os textos utilizados foram "What is racism?"15 de Ramon Grossfoguel (Artigo científico), "Brazilian women lead in science, technology and innovation, study shows"16 (artigo de opinião) por Sophia Huyer e Nancy Halfkin, "Brazilian judge approves 'gay conversion therapy', sparking national outrage" ${ }^{\prime 17}$, reportagem de Dom Philips no jornal The Guardian e "Indigenous as 'not-indigenous' as 'us'?: a dissident insider's views on pushing the bounds for what constitutes 'our mob", ${ }^{18}$ de autoria de Gordon Chalmers. Com diferentes gêneros textuais utilizados e textos para diferentes níveis de dificuldade, foi solicitado aos estudantes que transformassem os textos e seus gêneros textuais originais em outros gêneros textuais e outros textos. Além disso, eles tiveram que produzir um glossário de cada texto, dividido entre geral (com as palavras básicas que os alunos encontrassem nos textos, segundo suas dificuldades) e específico (com conceituação estimulada pelo professor, a ser definida no glossário pelo estudante, como "coloniality" no primeiro texto ou "aboriginality" no último texto). Em relação à reescrita dos textos em diferentes gêneros textuais, pensando nos gêneros do texto oral utilizados por Dolz e Schneuwly (2011), sugeri aos estudantes não ignorar os gêneros orais. Nesse caso, usando o texto "What is racism?", um dos grupos decidiu retextualizar o texto em uma manifestação (com cartazes feitos à mão, um vídeo em que eles interpretavam sobre as situações de racismo no cotidiano falando em inglês, incluindo os tipos de racismo descritos pelo autor, nomeadamente, o de cor, religioso, linguístico etc.).

\footnotetext{
${ }^{15}$ Available on < http://jwsr.pitt.edu/ojs/index.php/jwsr/article/view/609> .

${ }^{16}$ Available on <https://www.elsevier.com/connect/brazilian-women-lead-in-science-technology-andinnovation-study-shows $>$.

17 Available on <https://www.theguardian.com/world/2017/sep/19/brazilian-judge-approves-gayconversion-therapy>.

${ }^{18}$ Available on <https://eprints.qut.edu.au/91414/3/91414.pdf>.
} 


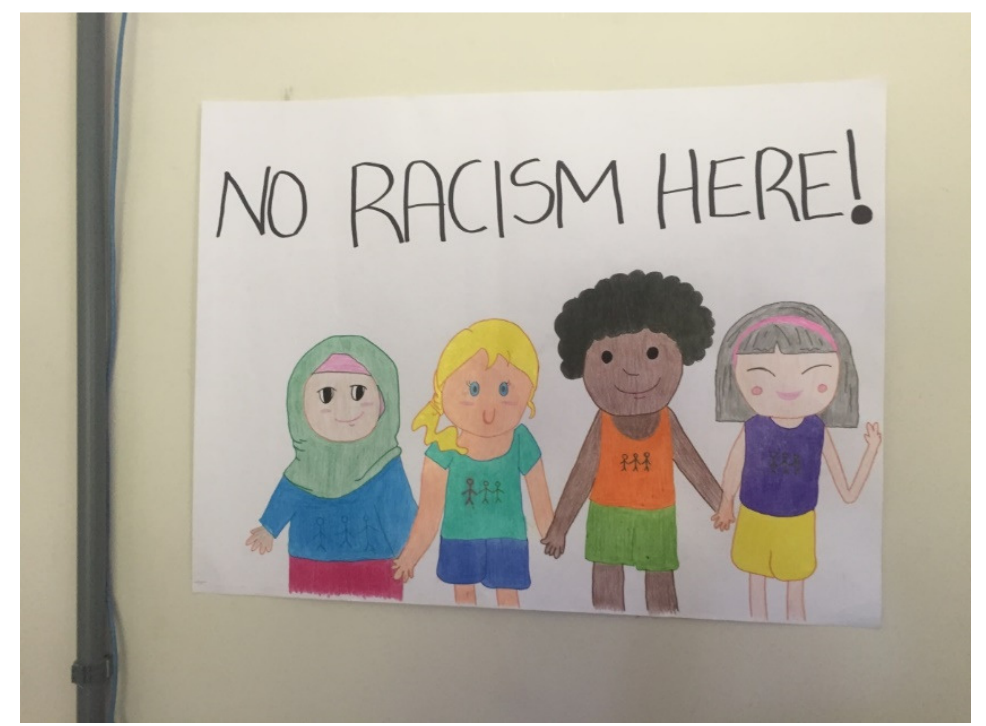

Figura 2- Retextualização do texto "What is racism?" através de uma manifestação na disciplina Compreensão Escrita em Língua Inglesa

Além disso, eles conduziram o chamado "jogo do privilégio"19, com a ajuda de estudantes brancos que cooperaram participando do jogo. Em vários aspectos, os estudantes negros demonstraram sua autoestima usando o inglês para criticar e desnudar o racismo estrutural durante as aulas de língua inglesa.

Finalmente, na disciplina Oficina de Textos de Língua Inglesa eu propus seminários para apresentar reescrita temática sobre os textos. A fim de ilustrar esses dados, os alunos de um dos grupos decidiram reescrever o texto "Remapping Writing: indigenous writing and cultural conflict in Brazil”20, de Lynn Mário Trindade de Meneses e Souza, ao realizar uma palestra enquanto gênero textual. Para a palestra, o grupo convidou um participante externo que, como líder indígena, respondeu a perguntas feitas pelos componentes do texto (com base no texto). Outro grupo com o mesmo tema escreveu um folheto artesanal e distribuiu para os colegas, que segue:

\footnotetext{
${ }^{19} \mathrm{O}$ jogo do privilégio, que pode ser visto aqui < https://www.youtube.com/watch?v=AOMpxsiUg2Q $>$, é uma dinâmica em que várias pessoas, de diferentes posições raciais, estão alinhadas e conduzidas por um apresentador. Ao passo que o apresentador cita vantagens de pessoas mais privilegiadas na base da sociedade (como "Dê um passo à frente se você estudou em escola particular"), as pessoas que tiveram aquele privilégio dão um passo à frente, e as pessoas mais racializadas vão ficando para trás, demonstrando como o racismo é uma entidade muitas vezes não percebida, mas que consiste na base da estruturação das exclusões sociais.

${ }^{20}$ Available on $<$

https://www.researchgate.net/profile/Lynn_Menezes_de_Souza/publication/242455202_Remapping_Writ ing_Indigenous_Writing_and_Cultural_Confl_ict_in_Brazil/links/54d7d3f20cf2464758182c84/Remappin g-Writing-Indigenous-Writing-and-Cultural-Confl-ict-in-Brazil.pdf> .
} 


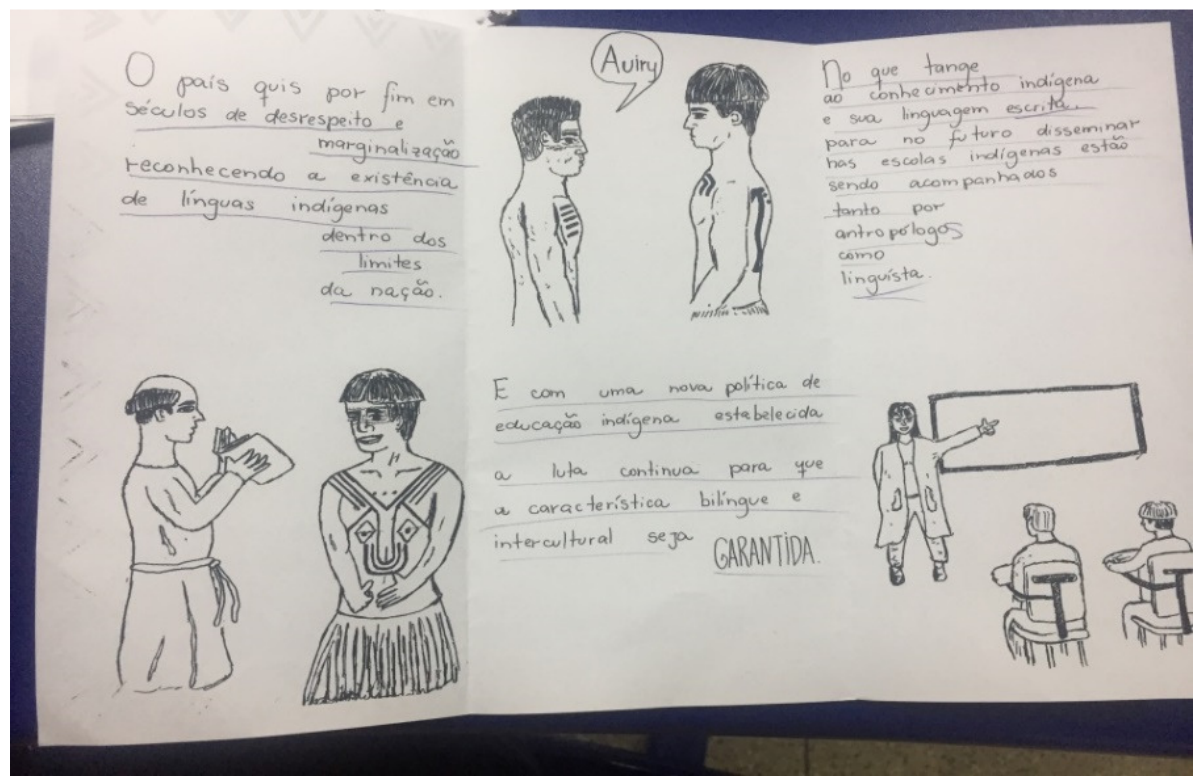

Figura 3- Folheto retextualizado do texto "Remapping Writing: indigenous writing and cultural conflict in Brazil" para a disciplina Oficina de Textos em Língua Inglesa (Bacharelado Interdisciplinar de Humanidades)

O panfleto apresentado pelos estudantes traduz em uma atividade de retextualização a própria discussão da etnicidade no sul da Bahia. Assim, nele os estudantes analisam o texto lido e o transformam na própria discussão dos conflitos indígenas que vitimam o povo Pataxó nessa região.

\section{ALGUMAS PALAVRAS FINAIS}

A pesquisa aqui apresentada faz parte de um projeto maior que busca investigar a relação entre raça e racialidade no contexto do aprendizado de línguas numa universidade no sul da Bahia. Os dados aqui apresentados compõem essa pesquisa, ainda em andamento, e permitem algumas discussões sobre as aulas de língua inglesa para alguns contextos de maioria negra ou não-branca, ou como possibiliade de desbranquear o pensamento.

No caso da universidade, o fato de estar instalada no Sul da Bahia, faz com que o debate racial esteja sempre presente no repertório político do seu cotidiano.

Os dados parciais permitem debater que a língua inglesa pode ser vista como advinda de uma globalização que é, na maioria das vezes, lida pelos estudantes como autoritária. No entanto, como buscamos apresentar através dos dados, todos esses conceitos estão em constante atualização através do próprio uso que as identidades racializadas fazem da língua inglesa. 
REVISTA X, Curitiba, volume 14, n.3,121-137, 2019.

As aulas críticas, com temas discursivos de identificação mais próxima com a região, permitiram o crescimento do interesse dos estudantes na língua a meu, o que pretendo demonstrar em trabalhos futuros através de dados. Por outro lado, a criatividade e a própria construção de um projeto de retextualização permitiram explorar o texto de maneira a compreender mais profundamente seus sentidos.

Os trabalhos aqui analisados permitem identificar que os temas dos textos eram temas dos cotidianos dos estudantes, que, na aula, podiam tratar deles também na língua “estrangeira". A língua, portanto, foi usada como um meio de ressignificar a opressão através de resistência.

Isso reforça em muito as discussões teóricas em torno de Mbembe (2014) e Moura (2014), de que os negros, mais do que signos de opressão, se transformam, através de suas próprias estratégias, em signos de resistência ao racismo.

Portanto, compreendemos aqui que as aulas de língua são espaços de desconstrução do racismo estrutural através do uso da língua, não como elemento em si, mas como um meio de debater questões das vidas dos próprios estudantes. Compreendemos ainda que, ao fazer isso, o professor/pesquisador estará desnudando a própria posição supostamente "neutra" de onde fala o professor de línguas, mas que, muitas vezes, produz desigualdades como a racial.

\section{REFERÊNCIAS}

APPIAH, K. A. Na casa de meu pai: a África na filosofia da cultura. Rio de Janeiro: Contraponto; 1997.

AZEVEDO, C. M. M. Onda negra medo branco: o negro no imaginário das elitesséculo XIX. Rio de Janeiro: Paz e Terra, 1987.

ANDERSON, B. Comunidades imaginadas: reflexões sobre a origem e a expansão do nacionalismo. Edição revisada. Londres: Verso, 1991.

COSTA, Sérgio. A mestiçagem e seus contrários - etnicidade e nacionalidade no Brasil contemporâneo. Tempo Social; Rev. Sociol. USP, S. Paulo, 13(1): 143-158, maio de 2001.

DUSSEL, E. D. 1492: O encobrimento do outro: a origem do 'mito da modernidade'. Petrópolis, RJ: Vozes, 1993.

FERREIRA, A.J.; CAMARGO, M. O racismo cordial nenhuma Livro didático de língua inglesa Aprovado Pelo PNLD. Revista da ABPN. Vol. 6, n. 12, 2013. p. 177202. 
REVISTA X, Curitiba, volume 14, n.3,121-137, 2019.

KUBOTA, R. Critical multiculturalism and second language education. In B. Norton \& K. Toohey (Eds.), Critical Pedagogies and Language Learning. Cambridge: Cambridge University Press, 2004.

KUBOTA, R. Rethinking the superiority of the native speaker: Toward a relational understanding of power. In: Neriko, M. Dorr (Ed.). Native speakers" revisited: Multilingualism, standardization, and diversity in language education (pp. 233-247). Mouton de Gruyter, 2009.

JORGE, M. L. S. Livros didáticos de línguas estrangeiras: construindo identidades positivas. In: FERREIRA, Aparecida J. (Org.). As políticas do livro didático e identidades sociais de raça, gênero, sexualidade e classe em livros didáticos. Campinas, SP: Pontes, 2014. p. 73-90.

MARX, K., A origem do capital: a acumulação primitiva. São Paulo: Centauro, 2000.

MBEMBE, A. Crítica da razão negra. Lisboa: Antígona, 2014.

MOURA, C. Rebeliões na senzala: quilombos, insurreições, guerrilhas. 5ed. São Paulo, Anita Garibaldi, 2014.

NASCIMENTO, Gabriel. As identidades de classe social/raça no ensino-aprendizagem de língua estrangeira: algumas considerações. Palimpsesto (Rio de Janeiro. Online), v. 23, p. 535-552, 2016.

PENNYCOOK, A. English and the discourses of Colonialism.London: Routledge, 2002.

PHILIPSON, R. Linguistic Imperialism.Oxford: Oxford University Press, 1992.

ROSA, J.; FLORES, N. Unsettling race and language: Toward a raciolinguistic perspective. Language in Society, 46, n.5, p. 621-647, 2017.

SANTOS, G. N.; MASTRELLA-DE-ANDRADE, M. R. O ensino de língua inglesa e a identidade de classe social: alguns apontamentos. Trabalhos em Linguística Aplicada., Campinas , v. 55, n. 3, p. 541-563, Disponível em s http://dx.doi.org/10.1590/010318135022177581>.

SOUZA, J. A tolice da Inteligência brasileira. Rio de Janeiro: LeYa de 2015.

SOUZA, N. S. Tornar-se negro. Rio de Janeiro: Edições Graal, 1983.

TILIO, R. C. ; A representação do mundo no livro didático de inglês como língua estrangeira: uma abordagem sócio-discursiva. The Especialist, v. 31, p. 167-192, 2010.

TÍLIO, R.C.; JÚNIOR, E. M. de S. Gênero e sexualidade em livros didáticos: impactos da avaliação do PNLD? In: FERREIRA, Aparecida J. (Org,). As políticas do livro didático e identidades sociais de raça, gênero, sexualidade e classe em livros didáticos. Campinas, SP: Pontes, 2014. p. 47-72. 